\title{
Expression levels of BCL2 and MKI67 in endometrial polyps in postmenopausal women and their correlation with obesity
}

\author{
MARIO VICENTE GIORDANO ${ }^{1,2}$, HIRAM DA SILVEIRA LUCAS ${ }^{1}$, \\ ROSSANO KEPLER ALVIM FIORELLI ${ }^{1}$, LUIZ AUGUSTO GIORDANO ${ }^{1}$, MARIO GÁSPARE GIORDANO ${ }^{1}$, \\ EDMUND CHADA BARACAT ${ }^{2}$ and JOSÉ MARIA SOARES JÚNIOR ${ }^{2}$
}

${ }^{1}$ Department of General and Specialized Surgery, Gaffrée e Guinle University Hospital (HUGG), Rio de Janeiro 20270-004;

${ }^{2}$ Department of Gynecology and Obstetrics, University of São Paulo (USP), São Paulo 05403-000, Brazil

Received January 22, 2020; Accepted September 1, 2020

DOI: $10.3892 / \mathrm{mco} .2020 .2139$

\begin{abstract}
Obesity is associated with numerous diseases, including endometrial disorders in postmenopausal women, such as adenocarcinoma, hyperplasias and endometrial polyps, and the risk of malignant transformation of these structures. The present study evaluated the influence of body mass index (BMI) on cell proliferation (BCL2 and MKI67) in endometrial polyps in postmenopausal women. A prospective cross-sectional study using immunohistochemical analysis of the expression of a cell proliferation marker (MKI67) and an anti-apoptotic gene (BCL2) in endometrial polyps in postmenopausal women was performed. The patients were divided into three groups depending on BMI: i) $<24.9 \mathrm{~kg} / \mathrm{m}^{2}$ (normal); ii) $>25$ and $<29.9 \mathrm{~kg} / \mathrm{m}^{2}$ (overweight); and iii) $>30 \mathrm{~kg} / \mathrm{m}^{2}$ (obese). The present study analyzed the expression of these markers in relation to polyp size, histological type and time since menopause in 38 patients. The interpretation of MKI67 and BCL2 expression accounted for the percentage of positive cells (scores): 1 (weak), $<5 \%$ of cells showed expression; 2 (moderate), between 5 and 50\%; and 3 (intense), $>50 \%$. Statistical analysis was performed using GraphPad InStat version 3.00 software. ANOVA was used to analyze BCL2 and MKI67 expression. A significance level of $\mathrm{P}<0.05$ was adopted for rejecting the null hypothesis. There was greater glandular expression of MKI67 in obese women than in normal weight women $(\mathrm{P}=0.02)$ and greater expression of BCL2 in the stroma of polyps $>2 \mathrm{~cm}$ $(\mathrm{P}=0.03)$. Hyperplastic polyps exhibited hyperexpression of MKI67 (P=0.04) compared with atrophic polyps. No difference in MKI67 and BCL2 expression was identified in the glands and stroma of polyps when comparing overweight and obese
\end{abstract}

Correspondence to: Professor Mario Vicente Giordano, Department of General and Specialized Surgery, Gaffrée e Guinle University Hospital (HUGG), 775 Rua Mariz e Barros, Maracanã, Rio de Janeiro 20270-004, Brazil

E-mail: mariovgiordano@gmail.com

Key words: endometrial neoplasms, menopause, polyps, obesity, cell proliferation postmenopausal patients. The present findings suggest that BMI has an influence on proliferation markers (MKI67) in the polyps of postmenopausal women and that polyps $>2 \mathrm{~cm}$ exhibit hyperexpression of BCL2 in the stroma.

\section{Introduction}

Obesity is a global problem and is associated with numerous diseases, including endometrial disorders in postmenopausal women, such as adenocarcinoma, hyperplasia and endometrial polyps and the risk of malignant transformation of these structures $(1,2)$.

The modernization of imaging exams in medicine in recent years has popularized the use of ultrasound, which is a simple and practical method for the study of the endometrium, especially in postmenopause, primarily in cases of bleeding. Consequently, the prevalence of endometrial polyps in the general population, suggested by transvaginal ultrasound, increased and ranges from 7.8 to $35 \%$ (3).

The pathogenesis of endometrial polyps is still unclear due to the wide variety of tumor types and their presence in different age groups. These polyps are considered risk factors for endometrial cancer; however, there is no consensus on the systematic excision of all identified polyps (2).

Microscopic analysis of endometrial polyps can identify glands and stroma. Although the endometrial tissue of some polyps has a cyclic functional reaction similar to that of the surrounding endometrium, in others, immature endometrium is observed, with irregular glands that are relatively insensitive to hormones (4).

However, in postmenopause, Pinheiro et al (5) found high expression of progesterone receptors (PRs), both in the glands and stroma of polyps in obese patients. It is possible that estrogenic activity in obese postmenopausal women causes the appearance of PRs in both glands and stroma (6).

Polyps contain stroma and thick-wall blood vessels, commonly found in the basal layer of the endometrium. They can be classified as atrophic, hyperplastic or malignant $(5,6)$.

The BCL2 gene regulates the permeability of the outer mitochondrial membrane and mainly has an anti-apoptotic function. This gene prevents cell death and, therefore, leads to uncontrolled cell proliferation, with the development of 
abnormal cell groups. BCL2 is considered a cancer-promoting factor that facilitates the action of other oncogenes $(5,7)$.

The MKI67 gene is associated with cell proliferation via ribosomal synthesis of ribonucleic acid. MKI67 antigens are present during the active phases of the cell cycle $\left(G_{1}, S, G_{2}\right.$ and mitosis) and absent in the other phase $\left(G_{0}\right)$. MKI67 is an excellent marker of cell proliferation and tumor aggressiveness (8).

As previously stated, obesity is a risk factor for the development of endometrial pathologies (2). However, the effect of body weight on the pathogenesis of endometrial polyps, apoptosis and cell proliferation is still unclear.

We studied the expression of markers of tissue proliferation (MKI67) and apoptosis (BCL2) in endometrial polyps in postmenopausal women and correlated it with obesity.

\section{Patients and methods}

Patient background. This was a cross-sectional, prospective study with histological and immunohistochemical analyses of endometrial polyps isolated from postmenopausal women between January 2016 and July 2018. Women with no menstrual bleeding for at least one year were included to characterize postmenopause; none presented with uterine bleeding. The initial diagnosis, suggested by transvaginal ultrasound, was endometrial polyps or endometrial thickening (endometrium measuring $5 \mathrm{~mm}$ or more). Obesity was defined as a body mass index (BMI) greater than $30 \mathrm{~kg} / \mathrm{m}^{2}$, overweight was defined as a BMI between 25 to $29.9 \mathrm{~kg} / \mathrm{m}^{2}$, and normal weight was defined as a BMI less than $24.9 \mathrm{~kg} / \mathrm{m}^{2}$.

Under general anesthesia, patients underwent hysteroscopy and polyp excision with a bipolar electrode and the Bettocchi system (Karl Storz ${ }^{\circledR}$ optical system, $2.9 \mathrm{~mm}$ ). Saline solution was used as a distending medium. The average time of the procedure was $25 \mathrm{~min}$, and no anesthetic or surgical complications were identified.

Fifty-nine patients were initially identified, but 24 were excluded for the following reasons: Presence of complex endometrial hyperplasia or endometrial cancer; refusal to participate in the study; and hormone therapy use. The remaining 38 patients were divided into groups as follows: 13 (normal weight), 14 (overweight) and 11 (obese). Age, time since menopause (in years), BMI, histopathology and endometrial polyp size ( $\geq 2$ or $<2 \mathrm{~cm}$ ) were analyzed.

Immunohistochemistry analysis. Analysis of MKI67 expression was performed by count in the field with highest expression ('hot spot') at 400x magnification. BCL2 expression was analyzed with a panoramic count at 10x and 100x magnification. Primary MKI67 antibodies (clone MIB-1; Dako; code: IR626, lot: 20024778, expiration date: 05/2019) and BCL2 antibodies (clone 124; Dako; code: IR614, lot: 20021755, expiration date: 02/2019) were used. The antibodies used were prediluted and ready-to-use (RTU) mouse monoclonal antibodies. A Dako Envision-Flex ${ }^{\circledR}$ detection and visualization system (code: SM802, lot: 10101615, expiration date: 05/2019) was used to visualize the immunoreactions.

The MKI67 and BCL2 expression data in endometrial polyps were interpreted according to the percentage of positive cells: Score $=1$ (weak: Less than $5 \%$ of cells showing expression); score $=2$ (moderate: Between 5 and $50 \%$ of cells showing expression); and score $=3$ (intense: More than $50 \%$ of cells showing expression). At least 10 fields were analyzed on each slide (Fig. 1).

Histopathological evaluation. The polyps were classified as atrophic (covered by flat to cuboidal columnar glandular epithelium) or hyperplastic (the response to estrogen was similar to that of diffuse endometrial hyperplasia). Histological sections (3- $\mu \mathrm{m}$ thick) were obtained with a manual microtome. Deparaffinization and antigen recovery were then performed in a single step with high $\mathrm{pH}$ buffer in a PT-Link module $\left(\right.$ Dako $\left.^{\circledR}\right)$. All slides had a positive and a negative control; a section of palatine tonsil with lymphoid hyperplasia was used as the positive control.

Statistical analysis. Statistical analysis was performed using GraphPad InStat version 3.00 for Windows 10 (GraphPad Software, Inc.). Kruskal-Wallis test was used to compare the three groups (nonparametric results-Kolmogorov-Smirnov test), and Dunn post hoc test when $\mathrm{P}<0,05$. For the comparative study between the two groups (histological type, polyp size and time since menopause), the nonparametric Mann-Whitney test was used (nonparametric results-Kolmogorov-Smirnov test). A level of significance of $\mathrm{P}<0.05$ was adopted to reject the null hypothesis.

Ethics approval. All patients were informed of the investigational nature of the study and provided written informed consent. The present study was conducted at Rio de Janeiro City, Federal University of the State of Rio de Janeiro. The study was approved by the Research Ethics Committee of the Gaffrée and Guinle University Hospital of Federal University of the State of Rio de Janeiro, no. 1,610,750.

\section{Results}

Groups of the study. Patients were distributed as follows: $29 \%$ obese (11/38), 37\% overweight (14/38) and 34\% normal weight (13/38). Analysis of MKI67 and BCL2 gene expression was performed both in glands and stroma (Fig. 1).

Immunohistochemistry and histophatology. We identified MKI67 hyperexpression in the glands of endometrial polyps in obese women compared to that in the glands of endometrial polyps in normal weight women $(\mathrm{P}<0.02)$. The other expression levels analyzed (glandular and stromal BCL2, and stromal MKI67) did not differ between groups (Table I). Histological analysis revealed that $29 \%$ (11/38) of the endometrial polyps were hyperplastic and $71 \%$ (27/38) were atrophic. In polyps larger than $2 \mathrm{~cm}$, hyperexpression of BCL2 was exhibited in the stroma $(\mathrm{P}=0.04)$. In hyperplastic polyps, the expression of MKI67 in the gland was higher than in the atrophic polyps $(\mathrm{P}=0.04)$ (Table II). Time since menopause (greater or less than 10 years) was not a relevant factor in the expression of cell proliferation (MKI67) or anti-apoptotic (BCL2) markers.

\section{Discussion}

Our study identified three genetic changes related to endometrial polyps: Hyperexpression of glandular MKI67 in polyps of 
Table I. BCL2 and MKI67 expression in endometrial polyps (stroma and gland), stratified by BMI.

\begin{tabular}{lcccc}
\hline Genes & BMI $<24.9$ & BMI $>25$ and $<29.9$ & BMI $\geq 30$ & P-value \\
\hline BCL2 G & $2.6 \pm 0.6$ & $2.8 \pm 0.3$ & $2.7 \pm 0.4$ & $0.71^{\mathrm{a}}$ \\
BCL2 S & $2.6 \pm 0.5$ & $2.7 \pm 0.4$ & $2.4 \pm 0.7$ & $0.69^{\mathrm{a}}$ \\
MKI67 G & $1.4 \pm 0.5$ & $1.5 \pm 0.5$ & $2.1 \pm 0.1$ & $0.02^{\mathrm{b}}$ \\
MKI67 S & $1.0 \pm 0.2$ & $1.0 \pm 0.2$ & $1.1 \pm 0.3$ & $0.85^{\mathrm{a}}$ \\
\hline
\end{tabular}

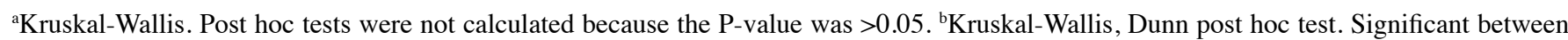
BMI $<24.9 \mathrm{~kg} / \mathrm{m}^{2}$ vs. BMI $>30 \mathrm{~kg} / \mathrm{m}^{2}$. The numbers presented in the table are the mean scores. BMI, body mass index; BCL2 G, BCL2 glandular; BCL2 S, BCL2 stromal; MKI67 G, MKI67 glandular; MKI67 S, MKI67 stromal; MKI67, marker of proliferation Ki-67.

Table II. BCL2 and MKI67 expression in endometrial polyps (stroma and gland), stratified by polyp size, histologic type and years since menopause.

\begin{tabular}{|c|c|c|c|c|c|c|c|c|c|}
\hline \multirow[b]{2}{*}{ Genes } & \multicolumn{3}{|c|}{ Polyp size } & \multicolumn{3}{|c|}{ Histologic type (polyp) } & \multicolumn{3}{|c|}{ Years since menopause } \\
\hline & $<2 \mathrm{~cm}$ & $\geq 2 \mathrm{~cm}$ & P-value & A & $\mathrm{H}$ & P-value & $<9$ years & $\geq 10$ years & P-value ${ }^{a}$ \\
\hline BCL2 G & $2.8 \pm 0.4$ & $2.6 \pm 0.6$ & 0.61 & $2.6 \pm 0.6$ & $2.8 \pm 0.3$ & 0.41 & $2.6 \pm 0.6$ & $2.7 \pm 0.5$ & 0.41 \\
\hline BCL2 S & $2.3 \pm 0.6$ & $2.7 \pm 0.4$ & 0.04 & $2.7 \pm 0.4$ & $2.5 \pm 0.6$ & 0.30 & $2.5 \pm 0.6$ & $2.7 \pm 0.4$ & 0.58 \\
\hline MKI67 G & $1.3 \pm 0.5$ & $1.5 \pm 0.5$ & 0.24 & $1.3 \pm 0.4$ & $1.7 \pm 0.4$ & 0.04 & $1.5 \pm 0.5$ & $1.5 \pm 0.5$ & 0.87 \\
\hline MKI67 S & $1.0 \pm 0.3$ & $1.0 \pm 0.2$ & 0.97 & $1.0 \pm 0.2$ & $1.1 \pm 0.3$ & 0.23 & $1.0 \pm 0.2$ & $1.1 \pm 0.3$ & 0.60 \\
\hline
\end{tabular}

${ }^{a}$ Mann-Whitney test. BCL2 and MKI67 expression in endometrial polyps was classified as 1 (weak), 2 (moderate) and 3 (intense). BCL2 G, BCL2 glandular; BCL2 S, BCL2 stromal; MKI67 G, MKI67 glandular; MKI67 S, MKI67 stromal; A, atrophic; H, hyperplasic; MKI67, marker of proliferation Ki-67.
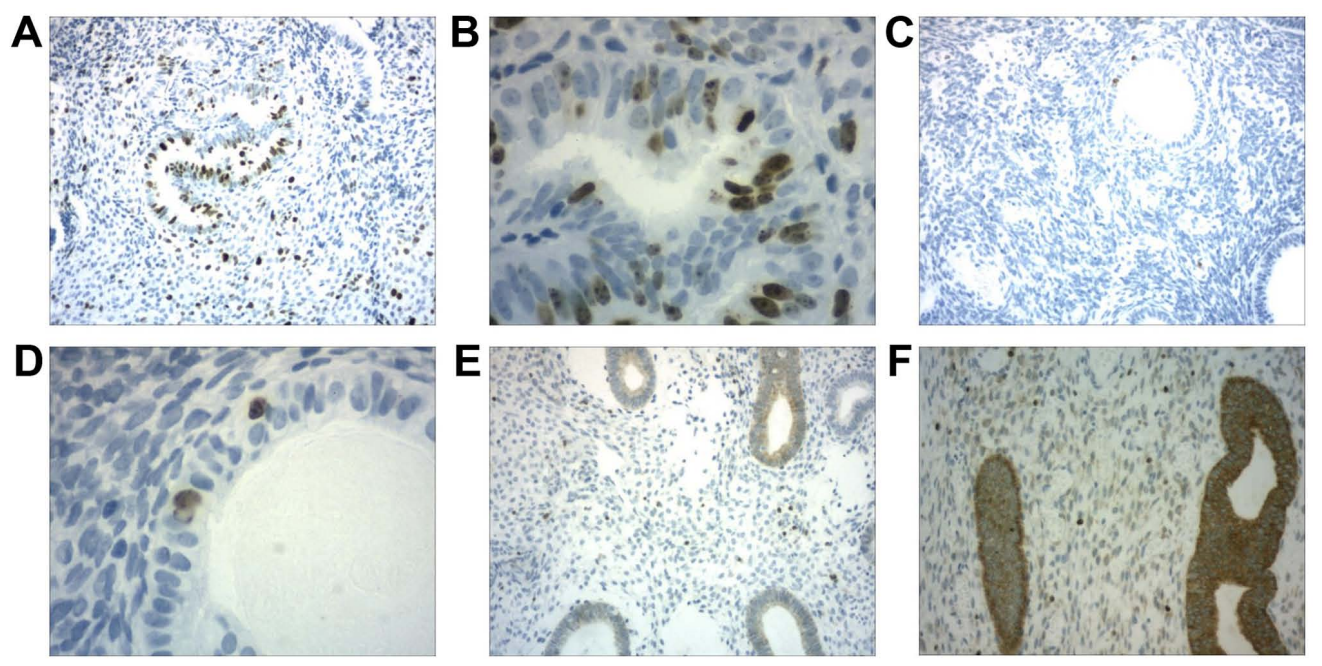

Figure 1. Immunohistochemistry of endometrial polyps. (A and B) Moderate expression of MKI67 in the gland and stroma. (A) Magnification, x100. (B) Magnification, x400. (C and D) Weak expression of MKI67 in the gland and stroma. (C) Magnification, x100. (D) Magnification, x400. (E) Weak expression of BCL2 in the stroma. Magnification, x100. (F) Strong expression of BCL2 in the gland and stroma. Magnification, x400. MKI67, marker of proliferation Ki-67.

obese women and in hyperplastic polyps and hyperexpression of stromal BCL2 in polyps larger than $2 \mathrm{~cm}$.

Doubt persists regarding the origin of endometrial polyps. It is possible that polyps originate in an area with intense endometrial basal cell proliferation. Vinatier et al (9) postulated the absence of apoptosis due to the hyperexpression of BCL2 in the epithelial cells of the basal layer of the endometrium, favoring the formation of these tumors.

Inceboz et al (10) found BCL2 hyperexpression in the glandular compartment of polyps in pre- and postmenopausal obese women, suggesting that the blockade of apoptosis is more important than the proliferative action of MKI67 (9). 
Arends (11) found hyperexpression of BCL2 in the basal layer of the endometrium throughout the menstrual cycle. This finding explains the regenerative capacity of the endometrium after menstruation, which allows basal cells to remain intact (10).

Our study did not identify BCL2 hyperexpression in the polyps in obese women. There was, however, BCL2 hyperexpression in the stroma of polyps larger than $2 \mathrm{~cm}$, regardless of BMI. Some molecular models assume that BCL2 protein inhibits apoptosis (keeping BAX-like proteins inactive) (5). This is consistent with the expression of this gene in endometrial cancers.

However, these models do not consider a property shared by all BCL2 proteins, which is their ability to promote, instead of inhibit, apoptosis under specific conditions (5). The complex interaction network that orchestrates the actions of these proteins is recognized as an enigmatic function of the BCL2 gene and constitutes an intricate and unresolved puzzle. We believe that this gene has limited apoptotic action, and after some specific stimulus (signaling), the loss of this ability favors uncontrolled cell proliferation. At that moment, there is a predominance of anti-apoptotic function with consequent tumor development.

This disruption of genetic function may be found in polyps with accelerated growth, larger than $2 \mathrm{~cm}$ in our study, and may increase the risk of malignant transformation of these tumors. In this line of thought, it would be prudent to excise all polyps larger than $2 \mathrm{~cm}$ in postmenopausal women, regardless of BMI, because BCL2 stromal hyperexpression would be a risk for disordered tissue proliferation due to the predominance of anti-apoptotic action.

Taylor et al (6) analyzed the expression of BCL2 and MKI67 in polyps during the proliferative and secretory phases of the menstrual cycle. The authors found hyperexpression of BCL2 in the gland and stroma compared to the surrounding endometrium during the proliferative phase. There was no difference in MKI67 expression in this phase of the cycle. During the secretory phase, there was no difference in the expression of these genes relative to that of the surrounding endometrium (4).

Gompel et al (12) found hyperexpression of BCL2 and MKI67 in the glandular tissue of polyps in the proliferative phase. In the secretory phase, MKI67 expression was higher but still lower than the level found in the proliferative phase. According to these authors, both BCL2 and MKI67 are interfering factors in polyp formation (11).

Some authors have analyzed the influence of ovarian steroids on the genesis of endometrial polyps through the expression of estrogen receptors (ERs) and PRs. In obese women, endometrial polyps presented hyperexpression in some studies (13). The results were conflicting, suggesting that a distinct stimulus, in addition to the hormonal stimulus, is necessary for tumor proliferation (4,11-14).

The predominance of estrogenic action in obese menopausal women explains these findings, with peripheral conversion of androgen into estrogen in adipose tissue (aromatase activity) $(15,16)$. This activity is more intense in obese women, especially after menopause. At this stage of life, there is no progesterone to counteract estrogenic activity, explaining estrogen's possible role in the origin of polyps and in the hyperexpression of ERs and PRs secondary to estrogenic activity (14). Oguz et al (17) agrees with this hypothesis (17).
This is a plausible hypothesis to explain the overexpression of MKI67 in the polyp glands of obese women in our study. There could be synergistic action of estrogen on the expression of MKI67, providing one of the possibilities for the increased risk of malignant transformation of these tumors in obese women. We also identified MKI67 hyperexpression when the histopathological analysis identified hyperplastic polyps. Is it possible that atrophic polyps have a lower risk of malignant transformation because there is no hyperexpression of MKI67? Would it be safe to just monitor them, avoiding unnecessary surgeries?

Pinheiro et al (5) found higher BCL2 expression in the glandular tissue of polyps in obese postmenopausal patients compared to non-obese patients $(\mathrm{P}<0.001)$. In the stroma, however, there was no significant difference in BCL2 expression $(\mathrm{P}=0.19)$. Regarding MKI67 expression, the authors found no difference between obese and non-obese postmenopausal patients (5).

Villavicencio et al (18) found 9.9-fold higher MKI67 expression in the endometrium of obese patients compared to non-obese patients. Obese women showed 12.6-fold higher proliferation than did normal weight women (18).

BCL2 is an oncogene involved in apoptosis, and its loss of expression is related to more aggressive endometrial cancer (higher grade, advanced stage and lymph node invasion). However, Stănescu et al (19) found no correlation between BCL2 expression and endometrial cancer grade or stage (19).

Troncon et al (20) evaluated the expression of genetic markers in the endometrial polyps of patients with and without postmenopausal bleeding (BCL2 and others). The authors found no significant differences between the two groups regarding the expression of risk factors genes for endometrial cancer studied or in relation to the clinical aspects evaluated (20).

There are still questions regarding the etiopathogenesis and treatment of endometrial polyps. Which patients should be monitored and which should undergo systematic polyp excision due to the risk of malignancy? It is known that there is an increasing number of polyp diagnoses, especially in postmenopause, which has resulted in a significant increase in public and private expenditures because of removal via hysteroscopic surgeries.

Our study attempted to stratify polyps according to risk to identify those requiring surgical treatment. We identified that the polyps of obese women and polyps larger than $2 \mathrm{~cm}$ present potential risks due to the hyperexpression of MKI67 and BCL2, respectively. Our study had a small sample size; therefore, further studies are needed to better answer these questions.

\section{Acknowledgements}

The authors would like to thank Dr Vera Lobo (Chief Pathologist of Branne/Lapac Pathological Anatomy, Cytopathology and Clinical Analysis Laboratories, Rio de Janeiro, RJ-Brazil) for the immunohistochemical analysis and interpretation of results.

\section{Funding}

No funding was received. 


\section{Availability of data and materials}

The datasets used and/or analyzed during the current study are available from the corresponding author on reasonable request.

\section{Authors' contributions}

MVG, LAG, MGG and HDSL performed clinical history, physical examination and hysteroscopy. RKAF, ECB and JMSJ helped in the preparation of the article and statistical analysis. All authors contributed to writing of the manuscript. All authors read and approved the final manuscript.

\section{Ethics approval and consent to participate}

All patients were informed of the investigational nature of the present study and provided their written informed consent. The present study was approved by the Research Ethics Committee of the Gaffrée and Guinle University Hospital of Federal University of the State of Rio de Janeiro (Universidade Federal do Estado do Rio de Janeiro-UNIRIO), number $1,610,750$.

\section{Patient consent for publication}

Not applicable.

\section{Competing interests}

The authors declare that they have no competing interests.

\section{References}

1. World Health Organization (WHO): Obesity and overweight WHO, Geneva, 2019. https://www.who.int/news-room/factsheets/detail/obesity-and-overweight. Accessed November 20 , 2019.

2. Onalan R, Onalan G, Tonguc E, Ozdener T, Dogan M and Mollamahmutoglu L: Body mass index is na independente risk factor for the development of endometrial polyps in patients unfergoing in vitro fertilization. Fertil Steril 91: 1056-1060, 2009

3. Costa-Paiva I, Godoy CE Jr, Antunes A Jr, Caseiro JD, Arthuso M and Pinto-Neto AM: Risk of malignancy in endometrial polyps in premenopausal and postmenopausal women according to clinicopathologic characteristics. Menopause 18: 1278-1282, 2011.

4. Dreisler E, Stampe SS, Ibsen PH and Lose G: Prevalence of endometria polyps and abnormal uterine bleeding in a Danish population aged 20-74 years. Ultrasound Obstet Gynecol 33: 102-108, 2009.
5. Pinheiro A, Antunes Jr A, Andrade L, Brot L, Pinto-Neto AM and Costa-Paiva L: Expression of hormone receptors, BCL2, Cox-2 and MKI67 in benign endometrial polyps and their association with obesity. Mol Med Rep 9: 2335-2341, 2014.

6. Taylor LJ, Jackson TL, Reid JG and Duffy SRG: The differential expression of oestrogen receptors, progesterone receptors, Bcl-2 and Ki67 in endometrial polyps. BJOG 110: 794-798, 2003.

7. Amezcua CA, Zheng W, Muderspach LI and Felix JC: Down-regulation of BCL2 is a potential marker of the efficacy of progestin therapy in the treatment of endometrial hyperplasia. Gynecol Oncol 73: 126-136, 1999.

8. Nogueira AA: Pólipos endometriais. Rev Bras Ginecol Obstet 27: 289-292, 2005.

9. Vinatier D, Dufour P and Subtil D: Apoptosis: A programmed cell death involved in ovarian and uterine physiology. Eur J Obstet Gynecol Reprod Biol 67: 85-102, 1996.

10. Inceboz US, Nese N, Uyar Y, Ozcakir HT, Kurtul O, Baytur YB, Kandiloglu AR, Caglar H and Fraser IS: Hormone receptor expressions and proliferation markers in postmenopausal endometrial polyps. Gynecol Obstet Invest 61: 24-28, 2006.

11. Arends MJ: Apoptosis in the endometrium. Histopathology 35: 174-178, 1999.

12. Gompel A, Sabourin JC, Martin A, Yaneva H, Audouin J Decroix Y and Poitout P: BCL2 expression in normal endometrium during the menstrual cycle. Am J Pathol 144: 1195-1202, 1994.

13. Mittal K, Schwartz I, Goswami S and Demopoulos R: Estrogen and progesterone receptors in the endometrial polyps. Int $\mathrm{J}$ Gynecol Pathol 15: 345-348, 1996.

14. Gul A, Ugur M, Iskender C, Zulfikaroglu E and Ozaksit G: Immunohistochemical expression of estrogen and progesterone receptors in endometrial polyps and its relationship to clinical parameters. Arch Gynecol Obstet 281: 479-483, 2010.

15. Belisario MSN, Vassallo J, Andrade LALA, Alvarenga M, Pinto GA and Monteiro IMU: The expression of the hormone receptors in the endometrium and endometrial polyps in postmenopausal women and its relationship to body mass index. Maturitas 53: 114-118, 2006.

16. Siiteri PK and Mac Donald PC: Role of extraglandular estrogen in human endocrinology. In: Handbook of Physiology. Geyer SR, Astwood EB and Greep RD (eds); Endocrinology, American Physiology Society, Washington DC, pp615, 1973.

17. Oguz S, Sargin A, Kelekci S, Aytan H, Tapisiz OL and Mollamahmutoglu L: The role of hormone replacement therapy in endometrial polyps formation. Maturitas 50: 231-236, 2005.

18. Villavicencio A, Aguilar G, Argüello G, Dünner C, Gabler F, Soto E, Gaete F, Peñaloza P, Celis M and Rojas C: The effect of overweight and obesity on proliferation and activation of AKT and ERK in human endometria. Gynecol Oncol 117: 96-102, 2010.

19. Stănescu AD, Nistor I, Potecã AG, Ditescu D and Comãnescu M: Prognostic biomarkers in endometrial adenocarcinoma. Rom J Morphol Embryol 55: 1339-1344, 2014.

20. Troncon JK, Meola J, Candido-Dos-Reis FJ, Poli-Neto OB, Nogueira AA and Rosa-E-Silva JC: Analysis of differential genetic expression in endometrial polyps of postmenopausal women. Climacteric 20: 462-466, 2017. 